\title{
Water Activity
}

\author{
O. F. Nielsen, M. Bilde, and M. Frosch \\ Department of Chemistry, University of Copenhagen, Universitetsparken 5, \\ 2100 Copenhagen, Denmark
}

Correspondence should be addressed to O. F. Nielsen, ofn@chem.ku.dk

Copyright (C) 2012 O. F. Nielsen et al. This is an open access article distributed under the Creative Commons Attribution License, which permits unrestricted use, distribution, and reproduction in any medium, provided the original work is properly cited.

\begin{abstract}
Microorganisms require water for their metabolic activities. Only a fraction of water in foodstuffs, the so-called free water, is available for this purpose. The amounts of free water previously estimated by two different methods (Frosch et al. (2010), Frosch et al. (2011), and Low (1969)) are compared for aqueous solutions of four electrolytes, $\mathrm{NaCl}_{1} \mathrm{NH}_{4} \mathrm{Cl}_{1} \mathrm{Na}_{2} \mathrm{SO}_{4}$, $\left(\mathrm{NH}_{4}\right)_{2} \mathrm{SO}_{4}$ : (i) vapour pressure measurements of the solutions relative to that of pure water (water activities) and (ii) lowwavenumber Raman spectra in the R $(\nu)$-representation. For each electrolyte deviations were found between results from the two methods. All water molecules in the illuminated volume contribute to the Raman data. The vapor pressure measurements refer to water molecules at the water/atmosphere interface where surface tension is important. Differences in surface tension for the four electrolytes qualitatively explain deviations between the amounts of "free water" observed by the two methods.
\end{abstract}

Keywords: Vapour pressure, water activity, bound water, raman spectroscopy, $\mathrm{R}(\nu)$-representation

\section{Introduction}

The concept of free and bound water is essential in an understanding of the role of water in all aspects of life sciences. Hydrogen bond vibrational modes give rise to bands in the IR and Raman region below $400 \mathrm{~cm}^{-1}$ [1]. This region has traditionally been difficult to access. In the Far-IR region the synchrotron light source is more efficient than the conventional globar [2-4]. In this region TeraHertz spectroscopy has recently become an important tool in studies of water/protein dynamics [5]. In Raman spectroscopy the very intense Rayleigh line extends to Raman shifts of several hundred wavenumbers. However, this problem can be solved by use of the $\mathrm{R}(\nu)$-representation [6-8]. Water/protein interactions in human and animal skin were previously investigated by low-wavenumber Raman spectroscopy in the $\mathrm{R}(\bar{\nu})$ representation, and a distinction between protein-bound water and "free" water was performed [6, 9]. A water band at $180 \mathrm{~cm}^{-1}$ was assigned to the presence of water with a tetrahedral hydrogen bond conformation $[6,9]$. This band is significant for water with a bulk-like structure, and the band was used to monitor the presence of "free water" in human skin hair and nail [10, 11], in photoaged and chronically aged skin [12], and in malignant and benign skin tumours [13]. In the present contribution the appearances of "free" water and water activity are discussed in relation to the preservation of foodstuffs. 


\section{2. "Free" Water and Water Activity}

Water activity, $a_{w}$, is an important factor in preservation of foodstuffs, and $a_{w}$ can be expressed as the vapour pressure of a water-containing substance, $p$, divided by that of pure water, $p_{0}$ at the same temperature [17]:

$$
a_{w}=\frac{p}{p_{0}}
$$

Water in food which is not bound to food molecules can support the growth of bacteria, yeasts, and molds (fungi) [18]. The term water activity, $a_{w}$, refers to this unbound and available water [18], also referred to as "free" water [19]. However, on a molecular scale it is not quite clear what the term "free" water refers to. A thorough understanding of the interplay between hydrogen bonded water structure and dynamics is still missing. Recently we have used low-wavenumber Raman spectroscopy in the $\mathrm{R}(\nu)$-representation to reveal the amount of translationally "free water" in aqueous salt solutions $[15,16]$. The intensity of a low-wavenumber band at $180 \mathrm{~cm}^{-1}$ was used to monitor water molecules in a tetrahedral configuration with four hydrogen bonds in aqueous solutions at various concentrations ( $m$ molal) of $\mathrm{NaCl}, \mathrm{NH}_{4} \mathrm{Cl}$, $\mathrm{Na}_{2} \mathrm{SO}_{4}$, and $\left(\mathrm{NH}_{4}\right)_{2} \mathrm{SO}_{4}$, respectively. Water molecules in a tetrahedral configuration were trapped in a potential minimum and consequently considered as "bound" water $[15,16]$. These molecules may be surrounded not only by other water molecules but also ions. The hydrogen-bonded water structures fluctuate with breaking and formation of hydrogen bonds, but in an average at a distinct temperature the amount of "bound" water is constant. Raman spectroscopy is a sufficiently fast technique to give an instant snapshot of the "bound water", that occurs even in pure liquid water. The amount of remaining water molecules with less than 3 hydrogen bonds per molecule was calculated, and a linear relation was assumed between the "free" molecules in a solution, $n_{w}^{\text {free }}(m)$, and in pure water, $n_{w_{0}}^{\text {free }}(m)$ :

$$
n_{w}^{\text {free }}(m)=b n_{w_{0}}^{\text {free }}(m) .
$$

Both $a_{w}$ and $b$ relate the amount of "free" water in an aqueous solution to that in pure liquid water. Thus the two parameters are expected to show the same concentration dependence. Water activities for the four electrolytes investigated were calculated from vapour pressure measurements by Low [14]. A comparison between $a_{w}$ obtained from [14] and $b$ obtained from [15, 16] is shown in Figure 1. For each electrolyte deviations between the two curves are observed. For solutions of $\mathrm{NaCl}, \mathrm{NH}_{4} \mathrm{Cl}$, and $\left(\mathrm{NH}_{4}\right)_{2} \mathrm{SO}_{4}$ the values for $a_{w}$ are higher than those for $b$ at a given electrolyte concentration. For solutions of $\mathrm{Na}_{2} \mathrm{SO}_{4}$ the opposite is found. The values of $b$ obtained according to (2.2) reflect the bulk of the aqueous solution, because all water molecules in the illuminated volume contribute. The vapour pressure (and $a_{w}$ ) relates to water molecules in the surface of the water. In this case the surface tension might be an important factor to take in to account. The surface tension reflects the tendency of water molecules to be drawn into the liquid. The surface tensions as a function of molal concentration show a linear dependence of the molality [20]. The slopes increase in the sequence $\mathrm{NH}_{4} \mathrm{Cl}<\mathrm{NaCl}$ $<\left(\mathrm{NH}_{4}\right)_{2} \mathrm{SO}_{4}<\mathrm{Na}_{2} \mathrm{SO}_{4}$ for the four electrolytes, the influence of the surface tension on the vapour pressure is expected to increase in this sequence. Assuming that the curves $b$ in Figure 1 describe the real content of "free" water in the solutions, the relative magnitudes of the surface tensions for the four electrolytes might explain the differences between $a_{w}$ and $b$ in Figure 1. For $\mathrm{Na}_{2} \mathrm{SO}_{4}$ solutions the water 


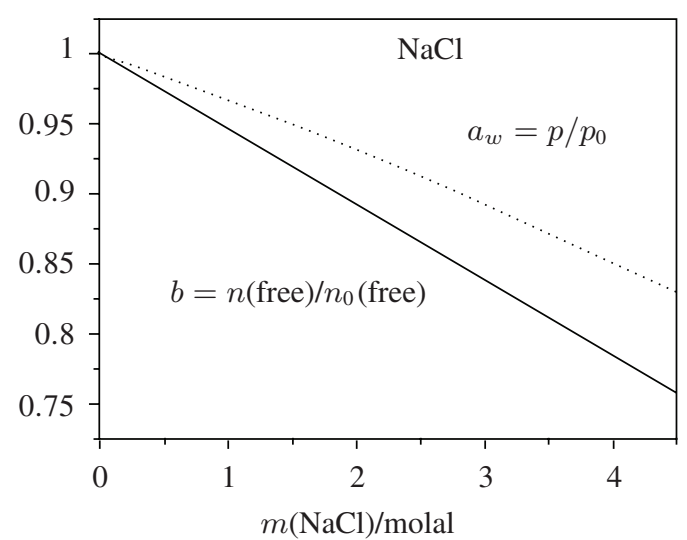

(a)

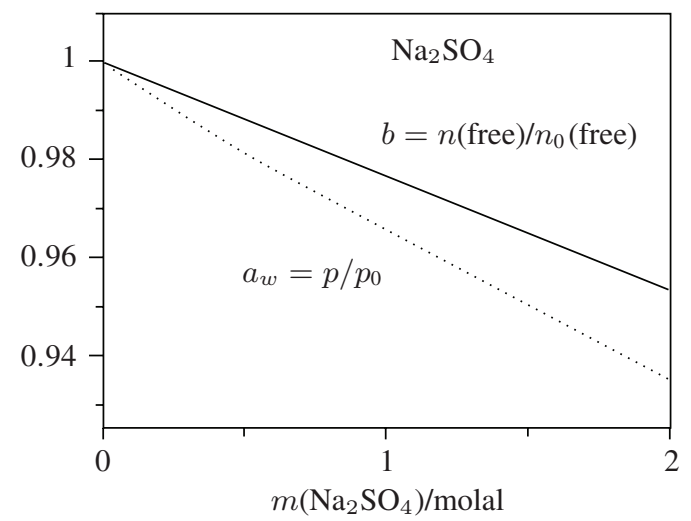

(c)

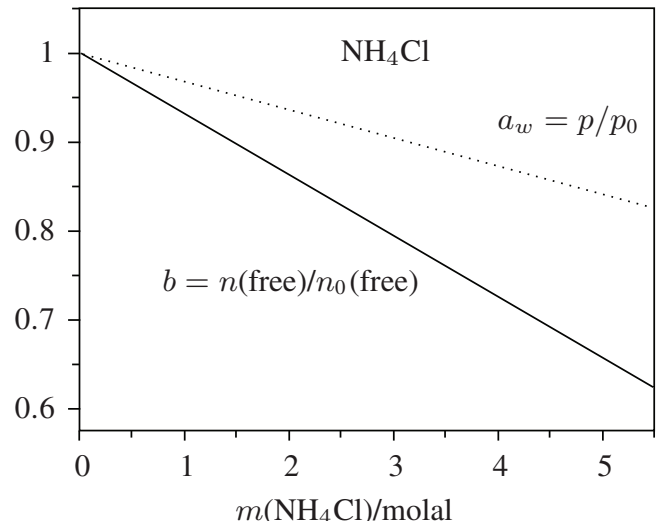

(b)

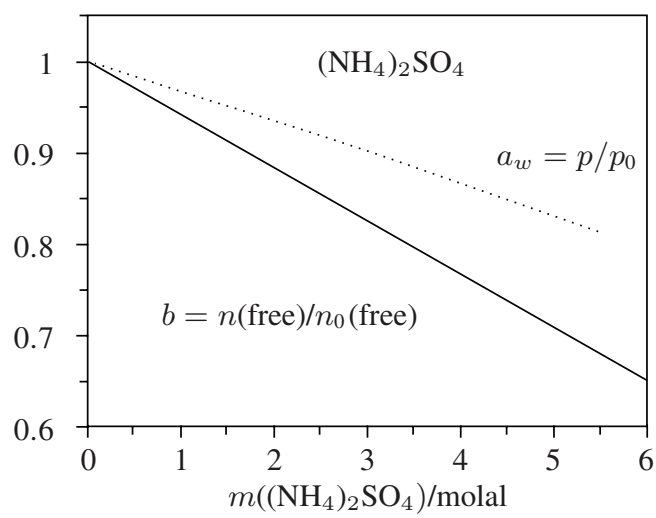

(d)

Figure 1: A comparison of water activity, $a_{w}$ (dotted lines) from [14], and translationally "free" water, $b$ (full lines) from $[15,16]$ in aqueous solutions of sodium - and ammonium chloride and sodium-and ammonium sulphate. All values refer to room temperature.

activities are lower than the $b$-curves. For the other three electrolytes the water activities are all above the $b$-curves in accordance with the lower surface tensions of these electrolytes.

\section{Conclusion}

A basic understanding of the "structure" of water and interactions between water and molecules/ions on a molecular level is essential in order to understand the role of water in biosystems. The water activity described by the vapour pressure of a water-containing substance relative to pure water is considered to show the amount of "free" water available to microorganisms. Thus this factor, although not well defined, is very important for the conservation of food, where microorganisms are unwanted. Water activities for aqueous solutions of four electrolytes $\left(\mathrm{NaCl}, \mathrm{NH}_{4} \mathrm{Cl}, \mathrm{Na}_{2} \mathrm{SO}_{4},\left(\mathrm{NH}_{4}\right)_{2} \mathrm{SO}_{4}\right)$ deviate from the amounts of translationally "free water" determined by low-wavenumber Raman spectra in the $\mathrm{R}(\nu)$-representation. In Raman spectroscopy all molecules in the illuminated volume contribute to the 
spectrum. Thus these measurements reflect the bulk of the solutions. The vapour pressure of water over a bulk solution is affected by the water/atmosphere interface. Differences in surface tensions of the solutions investigated might qualitatively explain the observed differences between Raman and vapour pressure measurements (water activities). A thorough understanding of the dynamics and interactions of water in biosystems is essential. Hopefully the preliminary results and hypothesis outlined here might contribute to further investigations of the presence of "free" and "bound" water in food and life sciences.

\section{Acknowledgment}

M. Frosch acknowledges support from Carlsbergs Mindelegat for Brewer J.C. Jacobsen.

\section{References}

[1] O. F. Nielsen, "Low-frequency Raman spectroscopy and biomolecular dynamics, a comparison between different low-frequency experimental techniques. Collectivity of vibrational modes," in Handbook of Raman Spectroscopy, From the Research Laboratory to the Process Line, I. R. Lewis and H. G. M. Edwards, Eds., pp. 593-615, Marcel Dekker, New York, NY, USA, 2001.

[2] T. M. Greve, K. B. Andersen, A. Engdahl, B. Nelander, and O. F. Nielsen, "Hydrogen bonding in proteins and water studied by Far-IR and low-wavenumber Raman spectroscopy," AIP Conference Proceedings, vol. 1075, pp. 13-17, 2008.

[3] T. M. Greve, K. B. Andersen, O. F. Nielsen, and A. Engdahl, "FTIR imaging and ATR-FT-Far-IR synchrotron spectroscopy of pig ear skin," Spectroscopy, vol. 24, no. 1-2, pp. 105-111, 2010.

[4] O. F. Nielsen, T. M. Greve, N. de Fries, N. W. Larsen, and A. Engdahl, "Low-wavenumber Raman and synchrotron studies of proteins and protein/water interactions. From model system to animal and human skin," AIP Conference Proceedings, vol. 1267, pp. 366-367, 2010.

[5] J. Xu, K. W. Plaxco, and S. J. Allen, "Probing the collective vibrational dynamics of a protein in liquid water by terahertz absorption spectroscopy," Protein Science, vol. 15, no. 5, pp. 1175-1181, 2006.

[6] S. E. M. Colaianni and O. F. Nielsen, "Low-frequency Raman spectroscopy," Journal of Molecular Structure, vol. 347, pp. 267-284, 1995.

[7] P. A. Lund, O. F. Nielsen, and E. Praestgaard, "Comparison of depolarized Rayleigh-wing scattering and far-infrared absorption in molecular liquids," Chemical Physics, vol. 28, no. 1-2, pp. 167-173, 1978.

[8] O. F. Nielsen, "The structure of liquid water. A low frequency $\left(10-400 \mathrm{~cm}^{-1}\right)$ Raman study," Chemical Physics Letters, vol. 60, no. 3, pp. 515-517, 1979.

[9] O. F. Nielsen, C. Johansson, K. L. Jacobsen et al., "Water structure and water/protein interactions in biological materials characterized by Raman spectroscopy," in Optical Devices and Diagnostics in Materials Science, D. L. Andrews, T. Asakura, S. Jutamulia et al., Eds., vol. 4098 of Proceedings of SPIE, pp. 160-168, 2000.

[10] M. Gniadecka, O. F. Nielsen, D. H. Christensen, and H. C. Wulf, "Structure of water, proteins, and lipids in intact human skin, hair, and nail," Journal of Investigative Dermatology, vol. 110, no. 4, pp. 393-398, 1998.

[11] T. M. Greve, N. R. Andersen, K. B. Andersen, M. Gniadecka, H. C. Wulf, and O. F. Nielsen, "Biomedical aspects of water structure in human and animal skin: a near infrared Fourier-transform Raman study," in New Approaches in Biomedical Spectroscopy, K. Kneipp, R. Aroca, H. Kneipp, and E. Wentrup-Byrne, Eds., vol. 963 of ACS Symposium Series, pp. 30-40, American Chemical Society, Washington, DC, USA, 2007. 
[12] M. Gniadecka, O. F. Nielsen, S. Wessel, M. Heidenheim, D. H. Christensen, and H. C. Wulf, "Water and protein structure in photoaged and chronically aged skin," Journal of Investigative Dermatology, vol. 111, no. 6, pp. 1129-1133, 1998.

[13] M. Gniadecka, O. F. Nielsen, and H. C. Wulf, "Water content and structure in malignant and benign skin tumours," Journal of Molecular Structure, vol. 661-662, no. 1-3, pp. 405-410, 2003.

[14] R. D. H. Low, "A theoretical study of nineteen condensation nuclei," Journal de Recherches Atmosphériques, vol. 4, pp. 65-78, 1969.

[15] M. Frosch, M. Bilde, and O. F. Nielsen, "From water clustering to osmotic coefficients," Journal of Physical Chemistry A, vol. 114, no. 44, pp. 11933-11942, 2010.

[16] M. Frosch, M. Bilde, and O. F. Nielsen, "Correction to 'From water clustering to osmotic coefficients'," Journal of Physical Chemistry A, vol. 115, no. 17, pp. 4563-4563, 2011.

[17] M. J. Blandamer, J. B. F. N. Engberts, P. T. Gleeson, and J. C. R. Reis, "Activity of water in aqueous systems. A frequently neglected property," Chemical Society Reviews, vol. 34, no. 5, pp. 440-458, 2005.

[18] 2011, http://www.cip.ukcentre.com/wa1.htm.

[19] 2011, http://www.pedak.nl/pdf/ISO\%2021807.pdf.

[20] E. W. Washburn, Ed., International Critical Tables of Numerical Data, Physics, Chemistry and Technology, vol. IV, National Research Council of the United States of America, New York, NY, USA; McGraw-Hill, London, UK, 1928. 


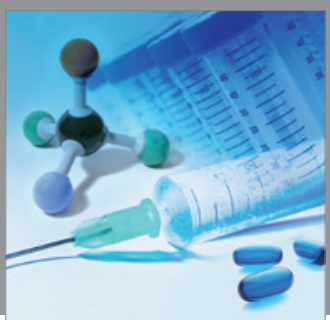

International Journal of

Medicinal Chemistry

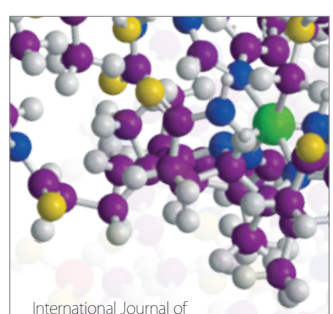

Carbohydrate Chemistry

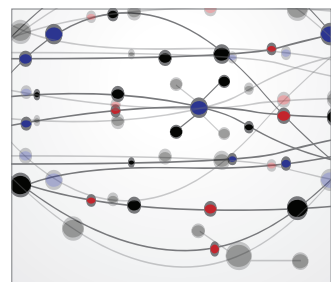

The Scientific World Journal
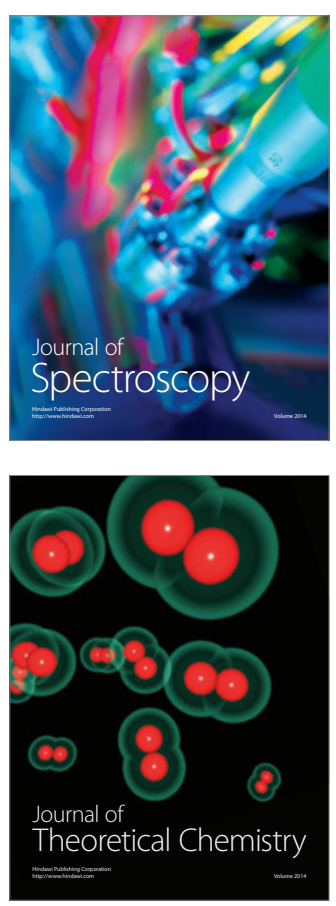
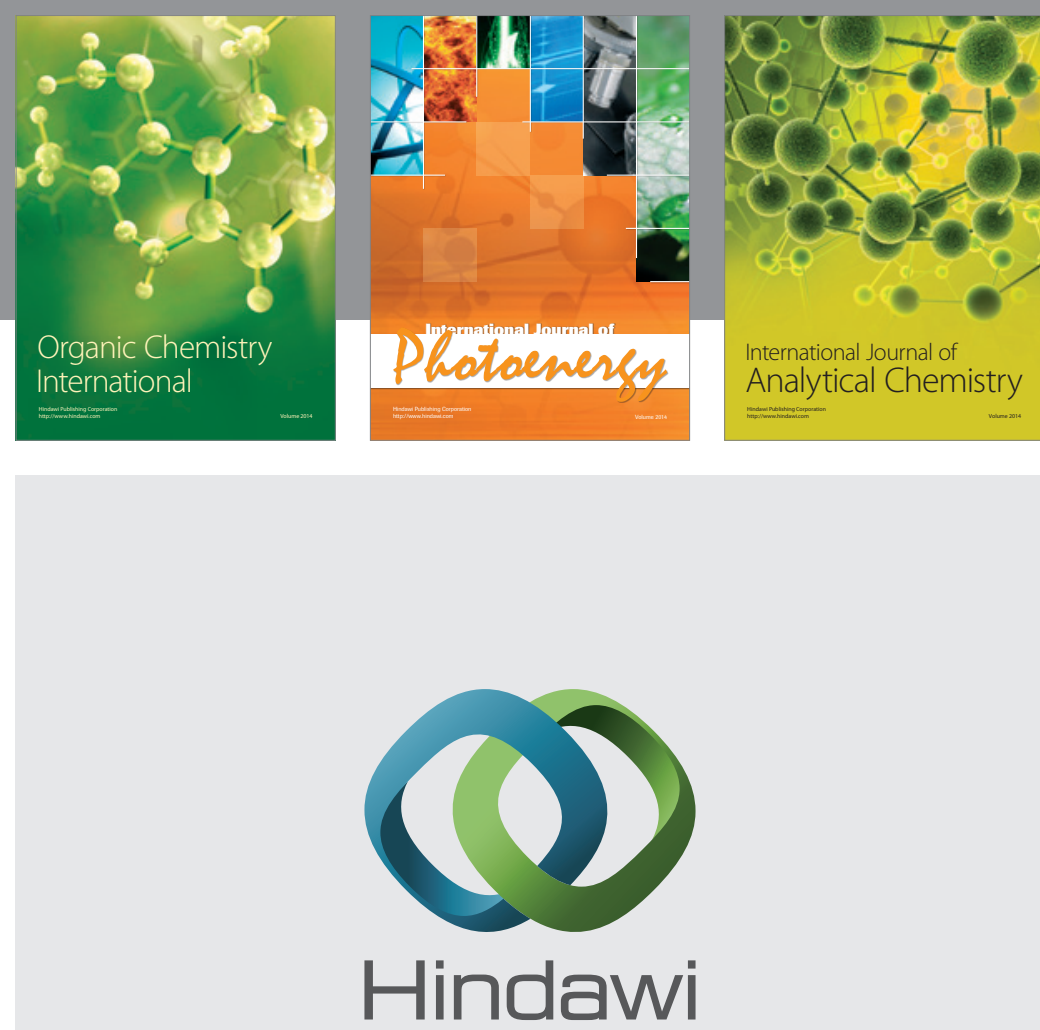

Submit your manuscripts at

http://www.hindawi.com
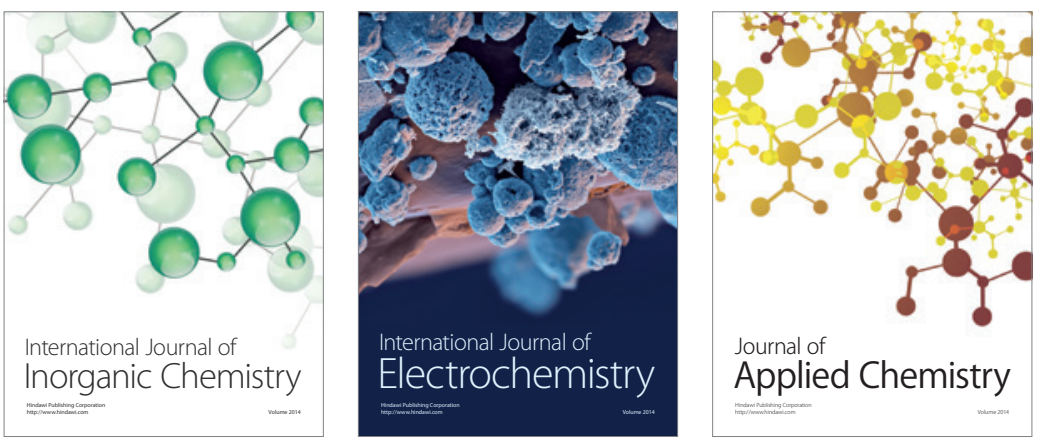

Journal of

Applied Chemistry
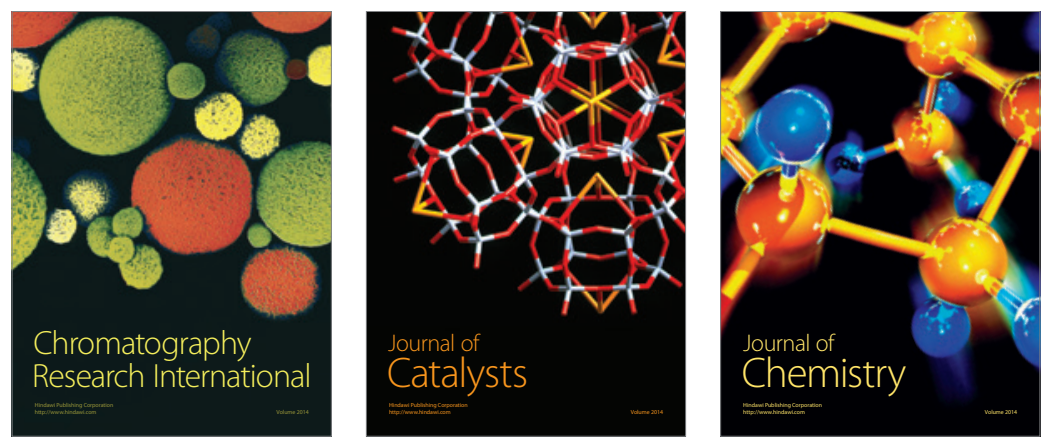
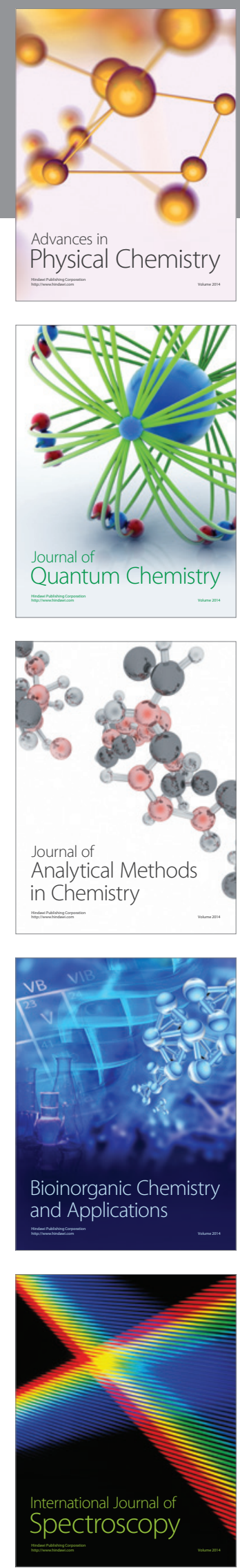